\title{
Essay
}

\section{Enhancing Interdisciplinary, Mathematics, and Physical Science in an Undergraduate Life Science Program through Physical Chemistry}

\author{
David P. Pursell \\ Georgia Gwinnett College, School of Science and Technology, Lawrenceville, GA 30043
}

Submitted June 18, 2008; Revised October 14, 2008; Accepted October 17, 2008

Monitoring Editor: Julio F. Turrens

\begin{abstract}
BIO2010 advocates enhancing the interdisciplinary, mathematics, and physical science components of the undergraduate biology curriculum. The Department of Chemistry and Life Science at West Point responded by developing a required physical chemistry course tailored to the interests of life science majors. To overcome student resistance to physical chemistry, students were enabled as long-term stakeholders who would shape the syllabus by selecting life science topics of interest to them. The initial $2 \mathrm{yr}$ of assessment indicates that students have a positive view of the course, feel they have succeeded in achieving course outcome goals, and that the course is relevant to their professional future. Instructor assessment of student outcome goal achievement via performance on exams and labs is comparable to that of students in traditional physical chemistry courses. Perhaps more noteworthy, both student and instructor assessment indicate positive trends from year 1 to year 2, presumably due to the student stakeholder effect.
\end{abstract}

\section{INTRODUCTION}

Much has been written on the topic of increasing the interdisciplinary approach to undergraduate biology education, to include enhancing the level of mathematics and physical sciences in life science programs (Kennedy and Gentile, 2003; National Research Council, 2003; Steitz, 2003; Bialek and Botstein, 2004; Gross et al., 2004; May, 2004; Slonczewski and Marusak, 2004). On the whole, it seems most agree that increasing interdisciplinary, mathematics, and physical sciences components of a life science program is a positive development. However, the challenge is balance of components in the curriculum. Professional associations and societies with an interest in undergraduate education have weighed in on this topic. One such organization is the American Society for Biochemistry and Molecular Biology (ASBMB), which advocates that a course in physical chemistry may be an appropriate addition to life science programs (http://asbmb.org/ asbmb/site.nsf/Sub/UndergradCurriculum?Opendocument; Bell, 2003; Boyle, 2003).

Coincident with these discussions in the literature and recognizing the importance of life science in the twenty-first

DOI: $10.1187 /$ cbe.08-06-0031

Address correspondence to: David P. Pursell (dpursell@ggc. usg.edu). century, the United States Military Academy at West Point added a life science major to its curriculum and changed the Department of Chemistry to the Department of Chemistry and Life Science. All students complete a 30-course core curriculum and an 11-course academic major of their choosing (Office of Policy, Planning, and Analysis, United States Military Academy, 2000; Office of the Dean, United States Military Academy 2002). The life science major is outlined in Figure 1. To enable students achieving the life science major program goals and to meet the intent of BIO2010, the department developed a new Physical Chemistry for Life Science course. The goals in developing this course were twofold: 1) because many students are resistant to physical chemistry, develop the course to maximize student engagement and design input with the intent to make it "their" course and thereby reduce resistance; and 2) to present a rigorous undergraduate physical chemistry course that enhances student application of mathematics and physical science to life science.

\section{METHODS}

\section{Physical Chemistry for Life Science Course}

"HONK IF YOU PASSED P-CHEM" is a well-known bumper sticker among chemistry students and faculty and exemplifies the formidable perception of physical chemistry. (Derrick and Derrick, 


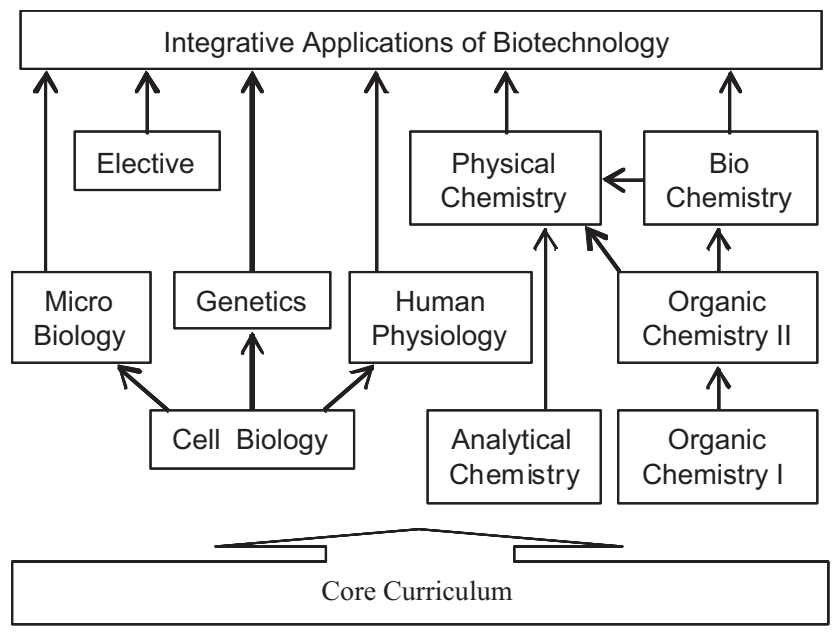

Figure 1. The United States Military Academy life science major.

2002). Students come to physical chemistry with negative perceptions and low expectations. Most students perceive concepts in physical chemistry to be abstract, too dominated by mathematics, and disconnected to everyday life. Most have no motivation and interest in physical chemistry and believe it would be easier to understand if more links could be made to everyday life (Sözbilir, 2004). Indeed, math experience and ability, study skills, and motivation all correlate in a positive way with success in physical chemistry (Nicoll and Francisco, 2001; Hahn and Polik, 2004).

With these ideas in mind, the department chose not to use part of its existing, traditional, two-semester physical chemistry sequence taken by chemists and engineers because it is typically math intensive, and students perceive that it has little application to life science. Rather, the department developed a course specifically tailored to life science students that was less math intensive and would connect fundamental concepts in a quantitative way to "their world" as life science majors. Furthermore, the department gave students a stake in the course by agreeing to modify the course topics from year to year based on student feedback. The psychological aspect of this student-driven evolution of course topics should not be minimized, because it helped students formulate the connection of physical chemistry to "their world" in a very direct way.

Before the first-year offering of Physical Chemistry for Life Science, the instructor met with students majoring in life science and discussed that the course would be required for them and taken during their senior year. Student feedback was limited to what they had heard from other students who had taken the traditional physical chemistry course - that it was very challenging, math intensive, and not relevant. Students stated that they felt confident in thermodynamics from their other courses, but otherwise were not familiar with physical chemistry topics. Therefore, students had little input in the design of the initial course beyond stating a significant attitudinal resistance. The instructor then collaborated with other faculty, reviewed the literature, and surveyed available texts before developing the course outcome goals (Table 1) and designing the initial course offering. Faculty also felt students were proficient with thermodynamics from their other courses but that they had little or no experience with quantum/statistical mechanics, advanced kinetics/dynamics, and spectroscopy. These topics were selected as the core of the initial course offering.

The course was designed to leverage the quantitative and analytical skills developed during the core academic program without an overreliance on mathematical knowledge and skill. The instructor built time into the class activities, homework assignments, and problem sets to teach and refresh student math skills. The course focused on setting up solutions to problems, analyzing units, and checking for reason-
Table 1. Physical Chemistry for Life Science course outcome goals

Goal Description

1 Appreciate the historical development of quantum mechanics within the context of the scientific method and understand and apply the fundamentals of quantum mechanics to life science systems

$2 \quad$ Understand and apply the physical and chemical basis of spectroscopies significant to life science

Understand molecular motion, kinetic energy, and the Maxwell-Boltzmann theory and their application in describing physical phenomena of life science systems

Understand the relationship of molecular motion, orientation, collisions, and energy as applied to rates of chemical reactions and how enzymes catalyze biochemical reactions

5 Apply the scientific method through a series of experiments to explore course outcome goals 1-4

ableness rather than calculating answers (calculators are not permitted on exams). In addition, students were provided summary data cards of relevant mathematical information for all exams. For example, the cards contain key equations so students do not have to memorize them, applicable portions of integration and differentiation tables, unit conversions, and relevant chemical data.

Approximately 40 life science majors take the course each year. Recognizing that student engagement and satisfaction are key to success of a physical chemistry course for life science students, the course was taught with three small sections of no more than 15 students rather than as one larger section of 40 students. The same instructor taught all of the sections during the first $2 \mathrm{yr}$, so this approach required a greater in-class time investment for the instructor than if teaching one large section, but resulted in enhanced opportunities for instructor-student engagement. At the beginning

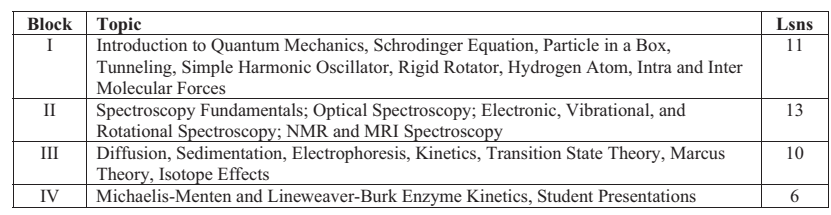

\begin{tabular}{|c|l|l|}
\hline Exp & Topic & Notes \\
\hline 1 & Photoelectric Effect and Particle-in-a-Box & Lab and Simulation \\
\hline 2 & Harmonic Oscillator and Tunneling & Lab and Simulation \\
\hline 3 & Radial Functions, Wavefunctions & Simulation \\
\hline 4 & $\begin{array}{l}\text { Rotational Spectroscopy and Boltzmann } \\
\text { Distribution }\end{array}$ & Lab and Simulation \\
\hline 5 & Magnetic Resonance Imaging & $\begin{array}{l}\text { Field trip: MRI Center at Keller Hospital. } \\
\text { Work with MRI technician; work with } \\
\text { radiologist on viewing "films" and diagnosis. }\end{array}$ \\
\hline 6 & Vibrational and Raman Spectroscopy & Lab and Simulation \\
\hline 7 & Kinetics & Lab \\
\hline
\end{tabular}

\begin{tabular}{|l|c|c|r|}
\hline \multicolumn{1}{|c|}{ Graded Event } & Iterations & Points & \multicolumn{1}{c|}{ Total } \\
\hline Daily readings and homework problems & Daily & 0 & 0 \\
\hline Laboratory experiments & 7 & 20 & 140 \\
\hline Problem Sets & 3 & 20 & 60 \\
\hline Presentation & 1 & 50 & 50 \\
\hline WPRs (hour exams) & 3 & 250 & 750 \\
\hline TEE (final exam) & 1 & 500 & 500 \\
\hline Total & & & 1500 \\
\hline
\end{tabular}

Figure 2. Physical Chemistry for Life Science course outline. 
Block I Problem Set

Name:

You are encouraged and permitted to collaborate with colleagues. If you receive assistance, you must document per $S O P$.

1. Evaluate the following integrals "by hand" (no calculators).
a. $\int \Delta \mathrm{H} / \mathrm{RT}^{2} \mathrm{dT}$
b. $\int-n R T / V d V$
e. $\int \cos a x d x$
c. $\int \mathrm{e}^{\mathrm{mx}} \mathrm{dx}$
f. $\int_{0}^{\pi} \sin \theta \mathrm{d} \theta$
d. $\int \sin \mathrm{kx} d x$
g. $\int \sin (2 \pi x / L) e^{-i k x} d x$
h. $\int_{0}^{L} \sin ^{2}(n \pi / L) x d x$ (note: $n=$ principal quantum number with values of $1,2,3, \ldots$ )

3. Write Euler's relations for the following.
a. $e^{i \theta}$
b. $\mathrm{e}^{-\mathrm{i} \theta}$

4. Write the equation for kinetic energy and then determine the derivative with respect to velocity. What is another name for the resulting term?

5. Review the Cartesian and Spherical Polar coordinate systems. Consider the system labeled below with angles $\theta$ and $\varphi$ and distances $r, a, b, c, d$ and point $(x, y, z)$ or $(r, \theta, \varphi)$.

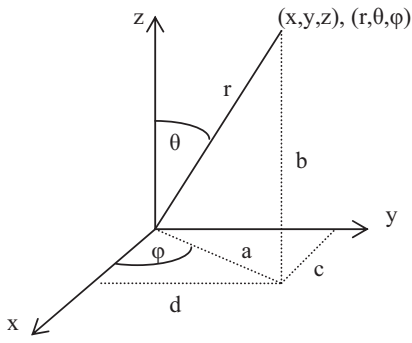

$$
\begin{aligned}
& \stackrel{\text { Limits }}{\mathrm{r}: 0 \rightarrow \mathrm{R}} \\
& \theta: 0 \rightarrow \pi \\
& \varphi: 0 \rightarrow 2 \pi
\end{aligned}
$$

a. Determine the values of $r, \theta, \varphi$ for the point $(3,-2,1)$.

b. Evaluate the triple integral of the differential volume element in spherical polar coordinates. The limits of $\varphi$ are from 0 to $2 \pi, \theta$ is from 0 to $\pi$, and $r$ is from 0 to $\mathrm{R}$. The differential volume element is given below.

$$
d \tau=(d r)(r \sin \theta d \varphi)(r d \theta)=r^{2} \sin \theta d r d \theta d \varphi
$$

Block II Problem Set

Name:

You are encouraged and permitted to collaborate with colleagues. If you receive assistance, you must document per SOP.

The reaction of hydroxyl radicals with carbon monoxide have been studied extensively with theoretical and experimental techniques. The reaction takes place via a transitory, energized [HOCO $]^{*}$ intermediate with a very short lifetime of about 0.4 to $2.7 \mathrm{ps}$. The geometry of the [HOCO]* intermediate is given below.<smiles>O=CC=O</smiles>

The $\mathrm{C}-\mathrm{O}$ bond distance is $2.23 \mathrm{a}_{0}, \mathrm{C}=\mathrm{O}$ bond distance is $2.53 \mathrm{a}_{\mathrm{o}}, \mathrm{O}-\mathrm{H}$ bond distance is $1.83 \mathrm{a}_{0}$. The H-O-C bond angle is $108.1^{\circ}$ and the $\mathrm{O}-\mathrm{C}-\mathrm{O}$ bond angle is $127.6^{\circ}$. You must set up your calculations with stubby pencil, to include appropriate constants and unit conversions. You may do the actual calculations via computer or calculator program.

1. Determine the center of mass of the $[\mathrm{HOCO}]^{*}$ intermediate. Sketch and label the $[\mathrm{HOCO}]^{*}$ intermediate on a Cartesian coordinate system with its center of mass at the origin. (Hints: The [HOCO $]^{*}$ intermediate is planar, so assume an initial center of mass as the $\mathrm{C}$ atom with the species in the $\mathrm{x}-\mathrm{y}$ plane. Recalculate the actual center of mass and plot the species in the $x-y$ plane with the center of mass at the origin $(0,0)$. You may work in distance units of $a_{0}$.)

2. Calculate the moments of inertia (inertial tensor) of the $[\mathrm{HOCO}]^{*}$ intermediate for rotation about each axis of the Cartesian coordinate system: $\mathrm{I}_{\mathrm{xx}}, \mathrm{I}_{\mathrm{yy}}, \mathrm{I}_{\mathrm{zz}}$.

\section{Block III Problem Set \\ Name: \\ You are encouraged and permitted to collaborate with colleagues. If you receive assistance, you must document per SOP.}

Derive the integrated rate equations (you have used these equations in other courses) for each of the four cases below. Your derivation should start with the appropriate rate expression and then show the mathematical manipulations to obtain the integrated rate equations. After obtaining each integrated rate equation, draw and label a plot on an x-y coordinate system as directed. You must do your work on this handout and use stubby pencil and integration tables for this problem set, not your computer.

Figure 3. Example problem sets. 
1. Zero-Order Reaction $(\mathrm{A} \rightarrow \mathrm{P})$. Plot $[\mathrm{A}]$ vs $\mathrm{t}$.
2. First-Order Reaction $(\mathrm{A} \rightarrow \mathrm{P})$. Plot $\ln [\mathrm{A}]$ vs t.
3. Second-Order Class I Reactions $(\mathrm{A}+\mathrm{A} \rightarrow \mathrm{P})$. Plot $1 /[\mathrm{A}]$ vs t.
4. Second-Order Class II Reactions $(\mathrm{A}+\mathrm{B} \rightarrow \mathrm{P})$. Plot $\ln \left\{[\mathrm{B}]_{\mathrm{o}}[\mathrm{A}] /[\mathrm{A}]_{\mathrm{o}}[\mathrm{B}]\right\}$ vs t.

Hint: to integrate the rate expression it is convenient to define a progress variable $\mathrm{x}$ which measures the progress of the reaction. The value of $\mathrm{x}$ increases as the reaction progresses. For the stoichiometric reaction $(\mathrm{A}+\mathrm{B} \rightarrow \mathrm{P})$ :

$$
[\mathrm{A}]_{\mathrm{t}}=\mathrm{a}-\mathrm{x} \text { with }[\mathrm{A}]_{\mathrm{o}}=\mathrm{a}
$$$$
[\mathrm{B}]_{\mathrm{t}}=\mathrm{b}-\mathrm{x} \text { with }[\mathrm{B}]_{\mathrm{o}}=\mathrm{b}
$$

So now the rate may be described as:

$$
\text { rate }=-\mathrm{d}[\mathrm{A}] / \mathrm{dt}=-\mathrm{d}[\mathrm{B}] / \mathrm{dt}=\mathrm{k}[\mathrm{A}][\mathrm{B}]=+\mathrm{dx} / \mathrm{dt}=\mathrm{k}(\mathrm{a}-\mathrm{x})(\mathrm{b}-\mathrm{x})
$$

Now separate variables ( $\mathrm{x}$ and $\mathrm{t}$ ) and integrate (partial fractions or integration tables), noting that $\mathrm{x}_{\mathrm{o}}=0$ and $\mathrm{t}_{\mathrm{o}}=0$.

Figure 3. (Continued)

of the course, students and instructor essentially agreed to a contract whereby students committed to preparing according to a detailed syllabus of lesson objectives, readings, terms and definitions, math refreshers, and homework problems before class, and the instructor committed to flexibility in facilitating student learning during class (Ertwine and Palladino, 1987; Dougherty, 1997; Toth and Montagna, 2002; The Teaching Professor, 2003). Each class period was 55 min long and because students had prepared in advance, there was sufficient time for discussion, exploration of more challenging topics in depth, and student recitation under the guiding and mentoring eye of the instructor, typically via student problem-solving chalkboard sessions. Lecture was rarely used and only when introducing a particularly challenging topic. The lab program of seven, 2-h labs was integrated with the class and reinforced classroom topics.

To provide perspective on the content of the course, the outline for year 1 of the course is shown in Figure 2. Course rigor is on par with what one finds in physical chemistry texts targeted to life science audiences (Atkins and de Paula, 2001; Tinoco et al., 2002; Atkins and de Paula, 2006; Hammes, 2007). In addition to daily readings and homework problems, students also completed problem sets (Figure 3 ) that provided additional mathematics review and practice. Students often chose to work collaboratively on the problem sets, further building teamwork and course esprit. Student achievement of the course outcome goals was assessed based on performance on exams and labs. As examples of the level of rigor of the course, the exams for year 2 are shown in Figure 4. The exams challenged students to apply material learned through the daily lessons in an integrated manner and were based upon the daily assignments, classroom activities, homework sets, and labs. Students also took a comprehensive final exam.

At the beginning of the course, the instructor discussed with students their status as stakeholders, that they would guide the syllabus for subsequent years, and that their input (warts and all) would be directly shared with students in subsequent years, to include the resulting syllabus changes inspired by their feedback. In year 2 of the course, the instructor detailed student feedback from year 1 and how student feedback had changed the structure and content of the course. For example, year 1 students took a short quiz at the beginning of each classroom session. Students found this daily quiz unproductive, so it was eliminated from year 2. Year 1 students took their third hour-long exam on the last day of class, just before going into the final exam period. Students found this generally unproductive, so for the second year the third exam was given 1 wk before the end of the semester, and the remaining lessons uncovered by an hour exam were incorporated into the final exam. Likewise with first-year content, such as eliminating Raman spectroscopy lessons and replacing it in year 2 with an expanded treatment of magnetic resonance imaging (MRI) spectroscopy. During year 2, feedback was gathered as students completed each of the course blocks. During the class period after taking the block exam, students led their own "after action review" (an Army technique that upper-level students are trained and proficient at conducting) and provided their comments to the instructor in the form of a short briefing. This enabled students to capture comments and insights just as the block ended and then provide this information to the instructor in a collective, nonattributable way rather than in an individual, attributable way. At the end of the course, students completed a formal written survey addressing attitudes about the course and their own assessment of whether they had met the course outcome goals. After the semester, the instructor met with other instructors in the life science program to obtain feedback probing what they had heard about the physical chemistry course from students.

\section{RESULTS AND DISCUSSION}

To illustrate the student-driven evolution of the course content, the course topics and number of lessons for each of the first 3 yr are summarized in Table 2. Although students had little input on the syllabus for the first year, students drove the evolution of topics for years 2 and 3 to more closely meet their interests so that in the course's third year the focus would be application of physical chemistry to analytical, spectroscopic, diagnostic, and surgical techniques used in the health professions, such as expanded treatment of MRI, positron emission tomography, and laser techniques. As course stakeholders, students determined the topics most interesting to them, enabling them to make direct connections to their world so that they would be more willing to take on the challenge of the physical chemistry course than if the instructor had dictated the course topics.

Assessment of the course over the first two offerings was directed at two objectives: student resistance to physical chemistry and enhancing application of mathematics and physical science to life science. The first objective was assessed primarily through student surveys. The second objective was assessed through student performance on exams and labs aligned with the course outcome goals.

All students completed an anonymous, Web-based survey (both Likert scale and free text response) at the end of the course. The survey probed student attitudes about the 


\section{Exam 1}

Problem I, 25 points. Briefly describe five (5) of the following six (6) terms for 5 points each.

1. Lennard-Jones Potential

2. Boltzmann Distribution of States

3. Work Function
4. Spherical Polar Coordinates

5. Orthogonality Condition for Wavefunctions

6. Coulomb's Law

Problem II, 40 points. Complete two (2) of the following three (3) problems. There is no extra credit.

(20) 1. The UV light responsible for sun tanning has a wavelength of about $360 \mathrm{~nm}$. Set up equation(s) and substitute values to determine the total energy (in Joules) absorbed by a person exposed to this radiation for 2.0 hours, given that there are $2.0 \times 10^{16}$ photons $/\left(\mathrm{cm}^{2}-\mathrm{sec}\right)$ of this wavelength hitting the Earth's surface, that the exposed body area is $0.45 \mathrm{~m}^{2}$, and only half of the radiation is absorbed while the other half is reflected by the body.

(20) 2. Consider a mobile E. coli cell of mass $1.0 \mathrm{pg}$ that can swim in a liquid or glide over surfaces by flexing tail-like structures known as flagella. A cadet monitored an $E$. coli cell during several experiments and determined its speed to within $1.0 \mu \mathrm{m} / \mathrm{sec}$. Set up the equation(s) and substitute values to determine the uncertainty in the cell's position.

(20) 3. Derive the de Broglie equation describing the relationship between particle momentum and wavelength. Hint: use Planck's relationship between the energy and frequency of light and Einstein's relationship between energy, mass, and the speed of light.

Problem III, 30 points. Antiparallel $\beta$-sheets are aligned to maximize dipole-dipole interactions while parallel $\beta$-sheets have less than optimal alignment. Given the depiction of antiparallel $\beta$-sheets below, set up the equation(s) and substitute values to determine the energy of the two intermolecular dipole-dipole interactions.

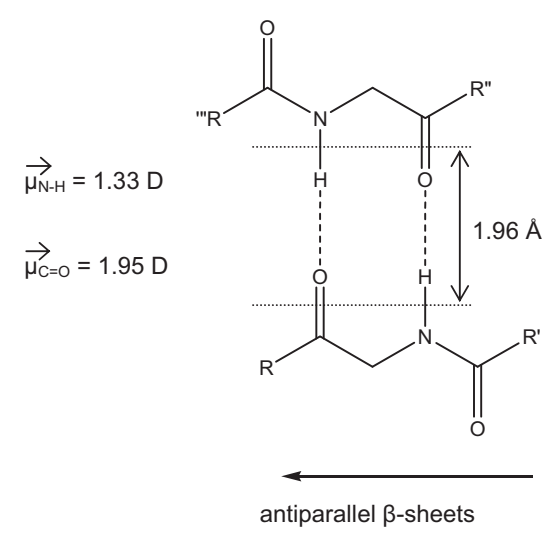

Problem IV, 95 points. $\beta$-carotene (shown below) is a symmetric conjugated polyene that when oxidized produces two molecules of retinal. The $22 \pi$-electrons are nearly free to roam throughout the full $2.94 \times 10^{-9}$ $\mathrm{m}$ length of the conjugated system. The $\pi$-electrons may be approximated as confined in a one-dimensional potential well using the particle in a box model.

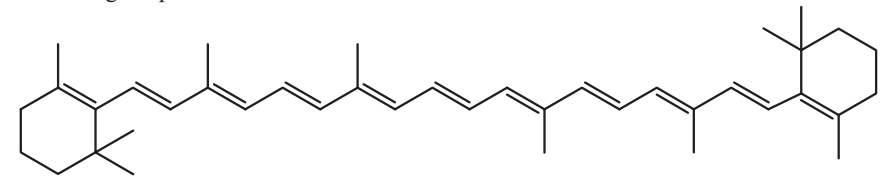

$\beta$-carotene

(4) 1. Write the equation for the energy of an electron in the box, $E_{n}$.

(4) 2. Write the wavefunction for the electron in the box, $\psi_{\mathrm{n}}$.

(15) 3. Demonstrate that the wavefunction, $\psi_{\mathrm{n}}$, is normalized. You must show your work.

4. Two square potential wells of length a are shown below.

(9) a. In both wells, draw and label the energy levels corresponding to the fundamental, first harmonic, and second harmonic. the left well.

(9) b. Draw the wavefunction, $\psi_{\mathrm{n}}$, for the fundamental, first harmonic, and second harmonic in

(9) c. Draw the probability distribution, $\psi_{\mathrm{n}}{ }^{2}$, for the fundamental, first harmonic, and second harmonic in the right well.

Figure 4. Example hour exams. Format is condensed by removing student work space. 


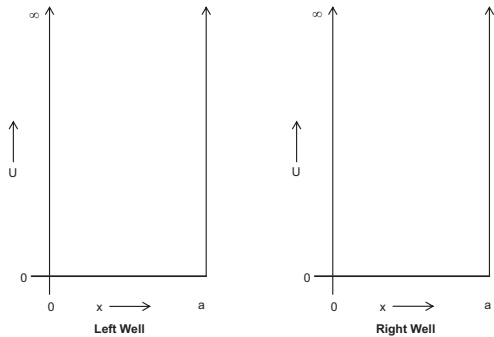

(30) 5. In the ground state of $\beta$-carotene, each molecular orbital is occupied by two electrons of opposite spin. The highest occupied molecular orbital (HOMO), also called the $\pi$ orbital, corresponds to $n=11$. The next higher energy level, which is the lowest unoccupied molecular orbital (LUMO) and is called the $\pi^{*}$ orbital, corresponds to $n=12$. Derive a general expression relating the wavelength of light, $\lambda$, and the length of the box, a, for the lowest energy, light induced electronic transition $\left(\pi \rightarrow \pi^{*}\right)$ of $\beta$-carotene.

6. A refined particle in a box model for $\beta$-carotene does not confine the $\pi$-electrons in a well with infinite potential walls.

(5) a. On the axis below, redraw the probability distribution, $\psi_{n}^{2}$, for $n=2$ to account for less than infinite potential walls.

(10) b. Briefly explain your drawing. As part of your explanation, contrast the effect of the less than infinite potential walls on $\pi$-electrons as compared to protons.

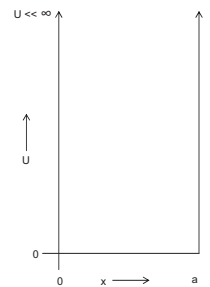

Problem V, 60 points. Atoms vibrate relative to one another in molecules with the bond acting like a spring. Consider the vibration of the N-H bond (force constant of $300 \mathrm{~N} / \mathrm{m}$ ) of the peptide linkage shown below. As a first order approximation, one may consider the relatively heavy $\mathrm{C}, \mathrm{N}$, and $\mathrm{O}$ atoms to form a stationary anchor for the very light $\mathrm{H}$ atom. Thus, only the $\mathrm{H}$ atom moves, vibrating as a simple harmonic oscillator.<smiles>CC(N)C(=O)N(C)C(P)C(=O)O</smiles>

(20) 1. Write the equation(s) and substitute values to determine the fundamental vibrational frequency of the N-H bond using the first order approximation.

2. Complete the following on the harmonic oscillator potential energy well below.

(9) a. Draw the energy levels for the fundamental, first, and second harmonic frequencies.

(9) b. Write the energy equation next to each level.

(9) c. On each of the three levels, draw the probability density, $\psi_{\mathrm{v}}{ }^{2}$.

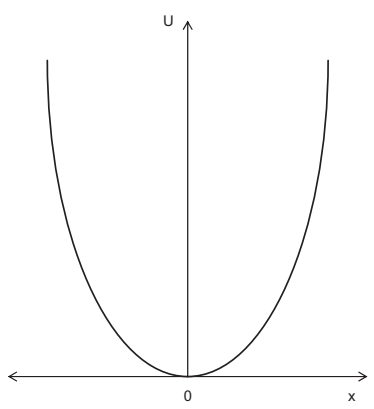

(13) d. Explain zero point energy and then describe how it is related to the Heisenberg Uncertainty Principle.

Figure 4. (Continued) 


\section{Exam 2}

Problem I, 20 points. Briefly describe four (4) of the following five (5) terms for 5 points each. Sketches, equations, words may assist. There is no extra credit.
1. Coupling Constant
4. Intersystem Crossing
2. Phosphorescence
5. Frank-Condon Principle
3. Quantum Yield

Problem II, 90 points. Complete three (3) of the following five (5) problems for 30 points each. For each part of Problem II, draw sketches, set up equations, do math manipulations, substitute values, convert units, but do not calculate. There is no extra credit.

(30) 1. A solution of optically active substance in a cell of $10 \mathrm{~cm}$ length shows an optical rotation of $250^{\circ}$ for $500 \mathrm{~nm}$ light. Determine the difference of the refractive indices of left and right circularly polarized light through this substance.

(30) 2. Demonstrate by carrying out the necessary integration that the eigenfunctions, $\psi$, for two states, $\mathrm{m}_{1}$ and $n_{1}$, of the Schrödinger equation for rotation in two dimensions are orthogonal when $m_{l} \neq n_{1}$ and $0 \leq \varphi \leq 2 \pi$.

$$
\psi\left(\mathrm{m}_{1}\right)=(1 / 2 \pi)^{1 / 2} \exp \left(\mathrm{im}_{1} \varphi\right) \quad \psi\left(\mathrm{n}_{1}\right)=(1 / 2 \pi)^{1 / 2} \exp \left(-\mathrm{in}_{1} \varphi\right)
$$

(30) 3. The energy difference between adjacent, low-lying rotational levels for small molecules is typically about $12 \mathrm{~J} / \mathrm{mol}$. Determine the temperature at which the population of the upper level is 4 (four) times greater than the population of the lower level.

(30) 4. Draw all of the normal modes of $\mathrm{CO}_{2}$, using the ball and stick format with arrows to show the relative motion of the atoms for each of the normal modes, then draw and label peaks for a predicted IR spectrum for gas phase $\mathrm{CO}_{2}$ on the chart below.

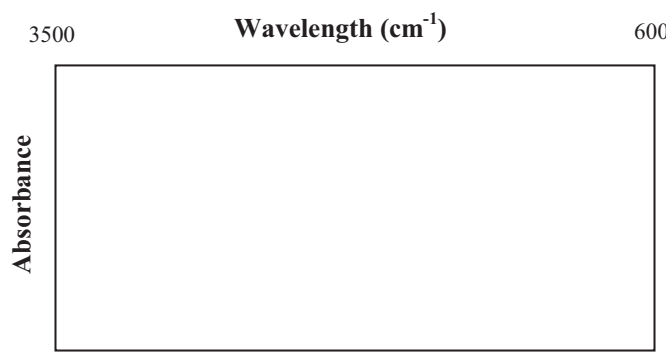

(30) 5. Magnetic Resonance Imaging (MRI) capitalizes on the notion that protons (the nucleus in an $\mathrm{H}$ atom, with a gyromagnetic ratio of $\gamma_{0}=42.54 \mathrm{MHz} / \mathrm{Tesla}$ ) in the human body possess spin and therefore generate their own magnetic field, M. A large external magnetic field of typically 2 Tesla in clinical settings, B, is applied to the human body in the MRI machine, causing the protons to both align and precess around the external magnetic field. $\mathbf{M}_{\mathbf{z}}$ is the projection of $\mathbf{M}$ on the z-axis and $\mathbf{M}_{\mathbf{x y}}$ is the projection of $\mathbf{M}$ on the $\mathrm{x}-\mathrm{y}$ plane. The MRI concept is illustrated in the sketch below.

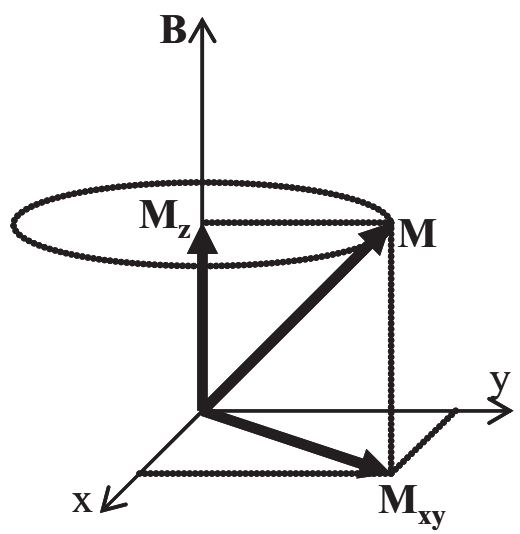

An external energy resonant pulse is then applied, causing the precessing proton to "flip" its alignment against the external magnetic field, B. Determine the energy of the external resonant pulse required to "flip" the proton.

Problem III, 60 points. All Problem III questions relate to Figure 1 below. Figure 1 has Energy on the yaxis and Position (r) on the $\mathrm{x}$-axis. Figure 1 contains 3 dotted curves representing 3 unique states of a generic molecule. Each dotted curve contains horizontal dotted lines representing sequential vibrational levels. The lowest energy vibrational level for each of the 3 curves is labeled $v=0$. Finally, there is a solid, bold vertical arrow parallel to the energy axis

Figure 4. (Continued) 


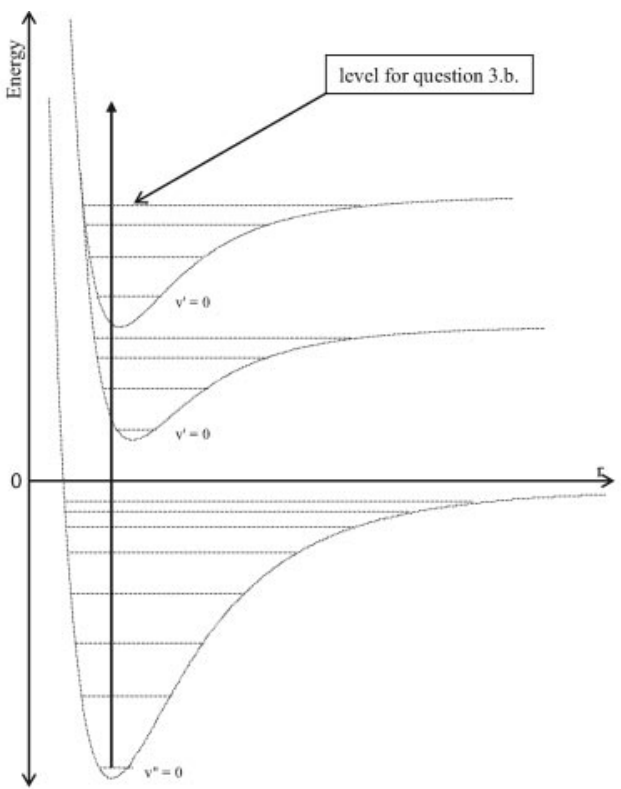

(16) 1 . Label/draw the following terms on Figure 1.
a. ground electronic state.
c. ground state bond dissociation energy
b. excited singlet electronic state.
d. excited triplet electronic state surface.

2. Consider the lower dotted curve of Figure 1 and its vibrational level, $\mathrm{v}^{\prime \prime}=0$.

(4) a. Draw and label (with appropriate J" value) the first 2 rotational levels in the $\mathrm{v}^{\prime \prime}=0$ vibrational level.

(4) b. Label each of the rotational levels of 2.a. with the value of their corresponding rotational energy.

3. Consider electronic transitions from the lowest dotted curve in Figure 1 to the upper dotted curves of Figure 1.

(12) a. Draw and label an arrow representing the most probable vertical transition from the lower dotted curve with $v^{\prime \prime}=0, J^{\prime \prime}=0$ to the appropriate excited electronic state dotted curve with $v^{\prime}=0, J=0$.

(12) b. Electronically excited molecules are quenched on a rapid time scale. Consider an excitation to the level indicated in Figure 1 as "level for 3.b." Draw and label the process of radiation-less energy quenching from the "level for 3.b." to the lowest energy level of this excited electronic state.

(12) c. As a continuation of your solution to part 3.b., draw and label the process of energy quenching via fluorescence from the lowest energy level of this excited electronic state.

Problem IV, 80 points. All Problem IV questions relate to the gas state rotation-vibration spectrum of naturally occurring $\mathrm{HCl}$ at $298 \mathrm{~K}$ as shown in Figure 2 below. The $\mathrm{x}$-axis is energy in units of wavenumbers $\left(\mathrm{cm}^{-1}\right)$ and goes from $3100 \mathrm{~cm}^{-1}$ on the left to $2600 \mathrm{~cm}^{-1}$ on the right. The $\mathrm{y}$-axis is Absorbance. The R-branch is on the left, the Q-branch in the middle, and the P-branch on the right. The peaks of the spectrum correspond to simultaneous rotational-vibrational (rovibration) transitions in the molecule. Note that there are actually 2 very closely spaced lines, one of higher absorbance and one of lower absorbance, for each "peak" of the spectrum.

Figure 2

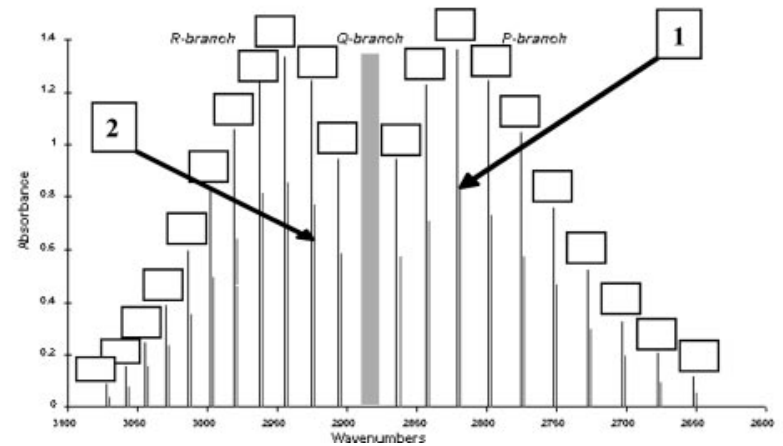

Figure 4. (Continued) 
1. In this question you will label several features on the spectrum shown in Figure 2.

(6) a. Using proper nomenclature, number each transition in both the P and R branches. Write the number in the box above each transition.

(16) b. Write the quantum numbers ( $\left.v^{\prime}, v^{\prime \prime}, J^{\prime}, J^{\prime \prime}\right)$ associated with the transition peaks labeled 1 and 2 in the spectrum.

$$
1 .
$$

2. Figure 3 below shows the first two vibrational levels (bold lines, $v^{\prime \prime}=0$ and $v^{1}=1$ ) for the $\mathrm{H}^{35} \mathrm{Cl}$ molecule and the rotational levels associated with each vibrational level. Energy increases moving up the diagram.

(6) a. On the sketch below, label each energy level with its $v$ and $J$ value.

(8) b. On the sketch below, draw 2 arrows representing the 2 simultaneous rotational-vibrational transitions that are labeled as 1 and 2 on Figure 2. Label each arrow you draw as either 1 or 2.

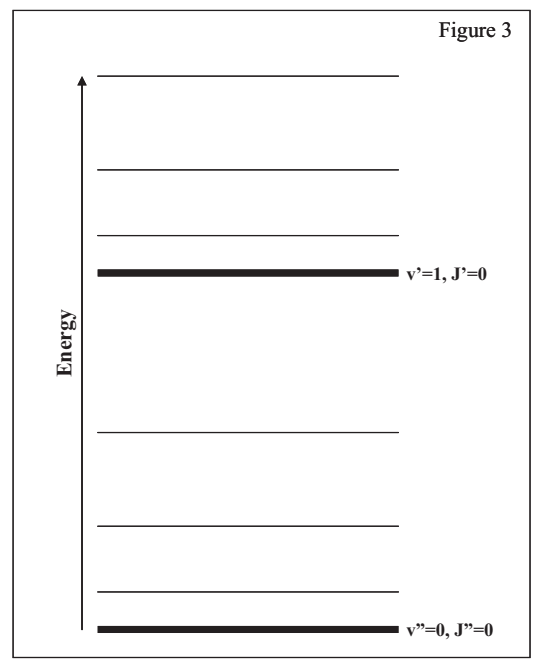

(44) 3. As described in the Problem IV statement, Figure 2 is the gas state rotation-vibration spectrum of naturally occurring $\mathrm{HCl}$ at $298 \mathrm{~K}$. As noted, there are actually 2 very closely spaced lines, one of higher absorbance and one of lower absorbance, for each "peak" of the spectrum. Derive a general equation that will allow you to determine the specific energy difference between the two lines that comprise each "peak." State any assumptions you make in solving this problem. Your general equation may be in symbols only.

You do not have to substitute numerical values. Do not calculate. Hint: Consider vibrational motion as modeled by the harmonic oscillator and rotational motion as modeled by the rigid rotator.

\section{Exam 3}

Problem I, 20 points. Briefly describe four (4) of the following five (5) terms for 5 points each. Sketches, equations, words may assist. There is no extra credit.

1. Brownian Motion

2. Electrophoretic Mobility

3. Transition State

\author{
4. Activation Energy \\ 5. Electron Transfer
}

Problem II, 90 points. Complete three (3) of the following four (4) problems for 30 points each. For each part of Problem I, draw sketches, set up equations, do math manipulations, substitute values, convert units, but do not calculate. There is no extra credit.

(30) 1. In a photochemical reaction $\mathrm{A} \rightarrow 2 \mathrm{~B}+\mathrm{C}$, the quantum efficiency with $500 \mathrm{~nm}$ light is $2.1 \times 10^{-2}$ $\mathrm{mol} \mathrm{B} / \mathrm{absorbed} \mathrm{einstein.} \mathrm{After} \mathrm{exposure} \mathrm{of} 300 \mathrm{mmol}$ of A to the light, $2.28 \mathrm{mmol}$ of B is formed. Determine the number of photons absorbed by A.

(30) 2. The concentration of nitrogen gas at $1.00 \mathrm{~atm}$ and $298 \mathrm{~K}$ is about $2.5 \times 10^{19}$ molecules $/ \mathrm{cm}^{3}$. Assuming the gas has a collision diameter of $3.75 \AA$, determine the average distance a molecule travels between successive collisions with other molecules.

(30) 3. Sedimentation is used to separate, purify, and analyze all sorts of biological molecules and is governed by the following equations.

$$
\mathrm{s}=\mathrm{u}_{\mathrm{t}} / \omega^{2} \mathrm{x}=\left\{\mathrm{m}\left(1-\overline{\mathrm{v}_{2}} \rho\right) \mathrm{N}_{\mathrm{o}} \mathrm{D}\right\} / \mathrm{RT}=2.303(\mathrm{~d} \log \mathrm{x}) / \omega^{2} \mathrm{dt}
$$

Boundary sedimentation centrifugation experiments of an unknown DNA molecule in $1 \mathrm{M} \mathrm{NaCl}$ at $20^{\circ} \mathrm{C}$ and 24,630 rpm yield the graph below. The unknown DNA has a partial specific volume in $1 \mathrm{M} \mathrm{NaCl}$ of $0.556 \mathrm{~cm}^{3} / \mathrm{g}$ and a diffusion coefficient of $6.03 \times 10^{-8} \mathrm{~cm}^{2} / \mathrm{sec}$. The $1 \mathrm{M} \mathrm{NaCl}$ has a viscosity of $1.104 \times 10^{-1}$ Pa-sec and a density of $1.04 \mathrm{~g} / \mathrm{cm}^{3}$.

Figure 4. (Continued) 


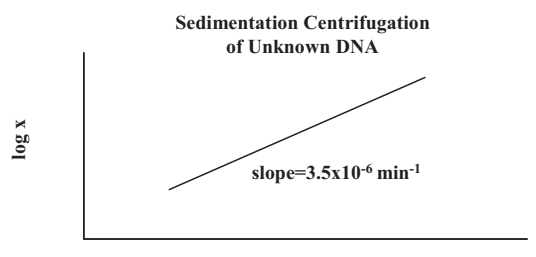

Time (minutes)

Determine the molecular weight of the unknown DNA.

(30) 4. Two types of $\mathrm{O}_{2}$-binding proteins are hemocyanin and hemerythrin, neither of which contains heme groups. Both proteins occur only in invertebrate animals. Hemocyanin, which consists of approximately $75 \mathrm{kD}$ subunits that each contain two $\mathrm{Cu}$ atoms ligated by His residues, is blue when oxygenated and colorless when deoxygenated. The activation energy for the denaturation of the $\mathrm{O}_{2}$-binding protein hemocyanin is $408 \mathrm{~kJ} / \mathrm{mol}$. Determine the temperature at which the denaturation rate of hemocyanin will be $10 \%$ faster than its rate at room temperature of $25^{\circ} \mathrm{C}$.

Problem III, 80 points. Ludwig Boltzmann and James Maxwell derived equations for the probability of finding a molecule with any chosen speed. The equation is derived from the Boltzmann most probable energy distribution, replacing the general energy term $\left(\mathrm{E}_{\mathrm{i}}\right)$ with kinetic energy $\left(\mathrm{KE}=1 / 2 \mathrm{mu}_{\mathrm{i}}^{2}\right)$. The result is the function $\mathrm{F}(\mathrm{u})$, the fraction of molecules with speed $\mathrm{u}$.

$$
F(u)=4 \pi\left(\frac{m}{2 \pi k T}\right)^{3 / 2} u^{2} e^{-m u^{2} / 2 k T}
$$

Shown below are three graphs of $\mathrm{F}(\mathrm{u}) \mathrm{vs}$. $\mathrm{u}$ for diatomic molecules at different temperatures.

(10) 1. Identify and label the $\mathrm{O}_{2}$ curve at $298 \mathrm{~K}$ and the $\mathrm{O}_{2}$ curve at $598 \mathrm{~K}$.

$\mathrm{F}(\mathrm{u}) \mathrm{v} . \mathrm{u}(\mathrm{m} / \mathrm{s})$ for $\mathrm{O}_{2}$ at $298 \mathrm{~K}$ and $598 \mathrm{~K}$

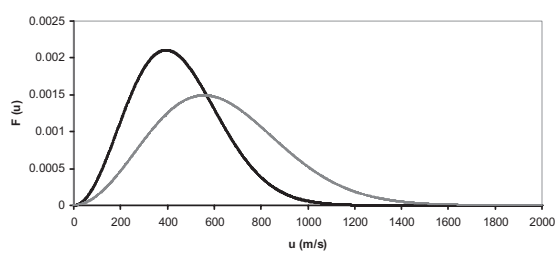

(10) 2. Identify and label the $\mathrm{O}_{2}$ curve and the $\mathrm{Br}_{2}$ curve at $598 \mathrm{~K}$.

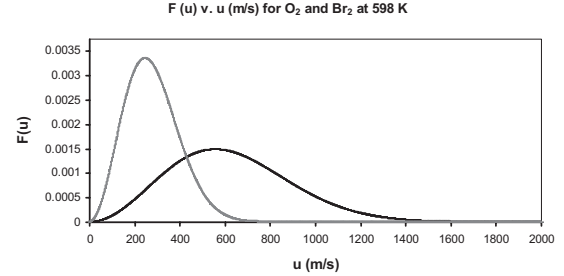

(10) 3. The following curve is for two diatomic molecules with isotopes of oxygen and chlorine, ${ }^{18} \mathrm{O}-{ }^{18} \mathrm{O}$ and $\mathrm{H}_{-}{ }^{35} \mathrm{Cl}$ at $598 \mathrm{~K}$. In this curve, both molecules have real molecular properties rather than the ideal properties used in formulating Kinetic Molecular Theory (KMT). Identify and label the real ${ }^{18} \mathrm{O}-{ }^{18} \mathrm{O}$ and $\mathrm{H}-{ }^{35} \mathrm{Cl}$ curves.

$\mathrm{F}(\mathrm{u}) \mathrm{v} . \mathrm{u}(\mathrm{m} / \mathrm{s})$ for ${ }^{18} \mathrm{O}-{ }^{18} \mathrm{O}$ and $\mathrm{H}^{35} \mathrm{Cl}$ at $598 \mathrm{~K}$

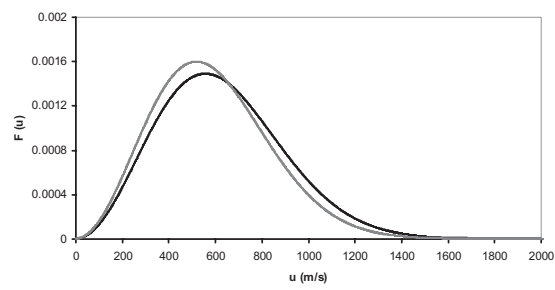

(10) 4. Briefly explain your rationale for labeling the real ${ }^{18} \mathrm{O}-{ }^{18} \mathrm{O}$ and $\mathrm{H}_{-}-{ }^{35} \mathrm{Cl}$ curves as you did in 3 . above.

(40) 5. The most probable speed for an unknown diatomic molecule at $298 \mathrm{~K}$ is $420.7 \mathrm{~m} / \mathrm{sec}$. Set up equations, complete math manipulations, substitute values, convert units, and explain how you would use the results to determine the identity of the unknown diatomic molecule.

Figure 4. (Continued) 
(40) 5. The most probable speed for an unknown diatomic molecule at $298 \mathrm{~K}$ is $420.7 \mathrm{~m} / \mathrm{sec}$. Set up equations, complete math manipulations, substitute values, convert units, and explain how you would use the results to determine the identity of the unknown diatomic molecule.

Problem IV, 60 points. Reaction of molecules adsorbed on a surface sometimes yield paradoxical results. For instance, the reaction of vinyl adsorbed on silver plus another vinyl adsorbed on silver yields 1,3butadiene gas that is not adsorbed on the silver surface. The overall reaction scheme is shown below.

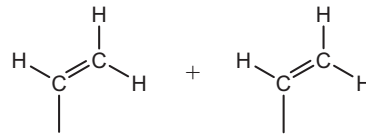

silver metal surface
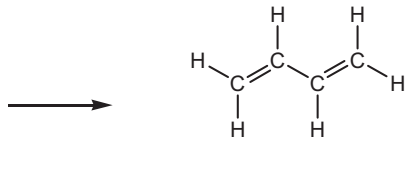

silver metal surface

The reaction may be written in summary form as follows.

$$
\mathrm{C}_{2} \mathrm{H}_{3} \text { (adsorbed) }+\mathrm{C}_{2} \mathrm{H}_{3} \text { (adsorbed) } \rightarrow \mathrm{C}_{4} \mathrm{H}_{6} \text { (gas) }
$$

One might expect that the reaction follows second order kinetics with a reaction scheme of $\mathrm{A}+\mathrm{A} \rightarrow \mathrm{P}$. However, the paradox is that experimental results show that the reaction follows first order kinetics with the generalized reaction scheme of $\mathrm{A} \rightarrow \mathrm{P}$.

(30) 1. Starting with the rate law, derive the integrated rate equation for the first order reaction of $\mathrm{A} \rightarrow \mathrm{P}$

(10) 2. Sketch a graph on the $x-y$ coordinate system showing how you would plot experimental data to demonstrate a first order kinetic process. Label all key features of the graph.

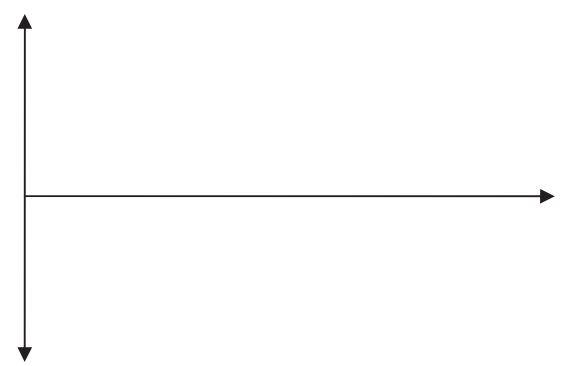

(20) 3. Propose a mechanism for $\mathrm{C}_{2} \mathrm{H}_{3}$ (adsorbed) $+\mathrm{C}_{2} \mathrm{H}_{3}$ (adsorbed) $\rightarrow \mathrm{C}_{4} \mathrm{H}_{6}$ (gas) that satisfies the experimentally determined first order kinetics.

Figure 4. (Continued)

course and how well students felt they had achieved the course objectives. Table 3 summarizes student course impressions after the first and second years of the course. The survey data indicate that for both years students overall had a positive impression of the course, noting that it was stimulating, challenging, increased motivation to continue learning, increased critical thinking, and encouraged collaborative learning. Of particular note, student impression from the first year to the second year improved in every survey category, with an average favorable (strongly agree + agree) increase in each category of $14 \%$. Although not proven by the data, one may infer that the more favorable student impressions in the second year were due in part to the student-driven evolution of topics covered via the "stakeholder effect," having the effect of making the course more relevant to their world. The survey also asked students how well they believed they had accomplished the five course outcome goals, with the data summarized in Table 4 . The majority of students felt they accomplished the course goals in each of the first 2 yr. Again, the students' perceived accomplishment increased for all five outcome goals from the first to the second year, with an average favorable increase for each objective of $24 \%$. Again, one may surmise that the perceived accomplishment increased in part because students felt they were stakeholders in the design of the course. The instructor assessed student accomplishment of the course outcome goals, and hence enhanced mathematics and physical science in life sciences, through student performance on exams and laboratories, with percent scores aggregated by outcome goal. The data are presented as averages by course outcome goal and summarized in Table 5. Based on the instructor's experience in comparison with traditional physical chemistry courses and scores, the average scores indicate respectable student achievement. Perhaps more significantly and consistent with student perceptions, student performance averages increased from the first to second year for all course outcome goals, with an average favorable increase of $5 \%$ for each objective.

Student free text comments were generally positive the first $2 \mathrm{yr}$ of the course, with representative positive and negative comments presented below. 
Table 2. Student-driven evolution of topics from initial offering to third year offering

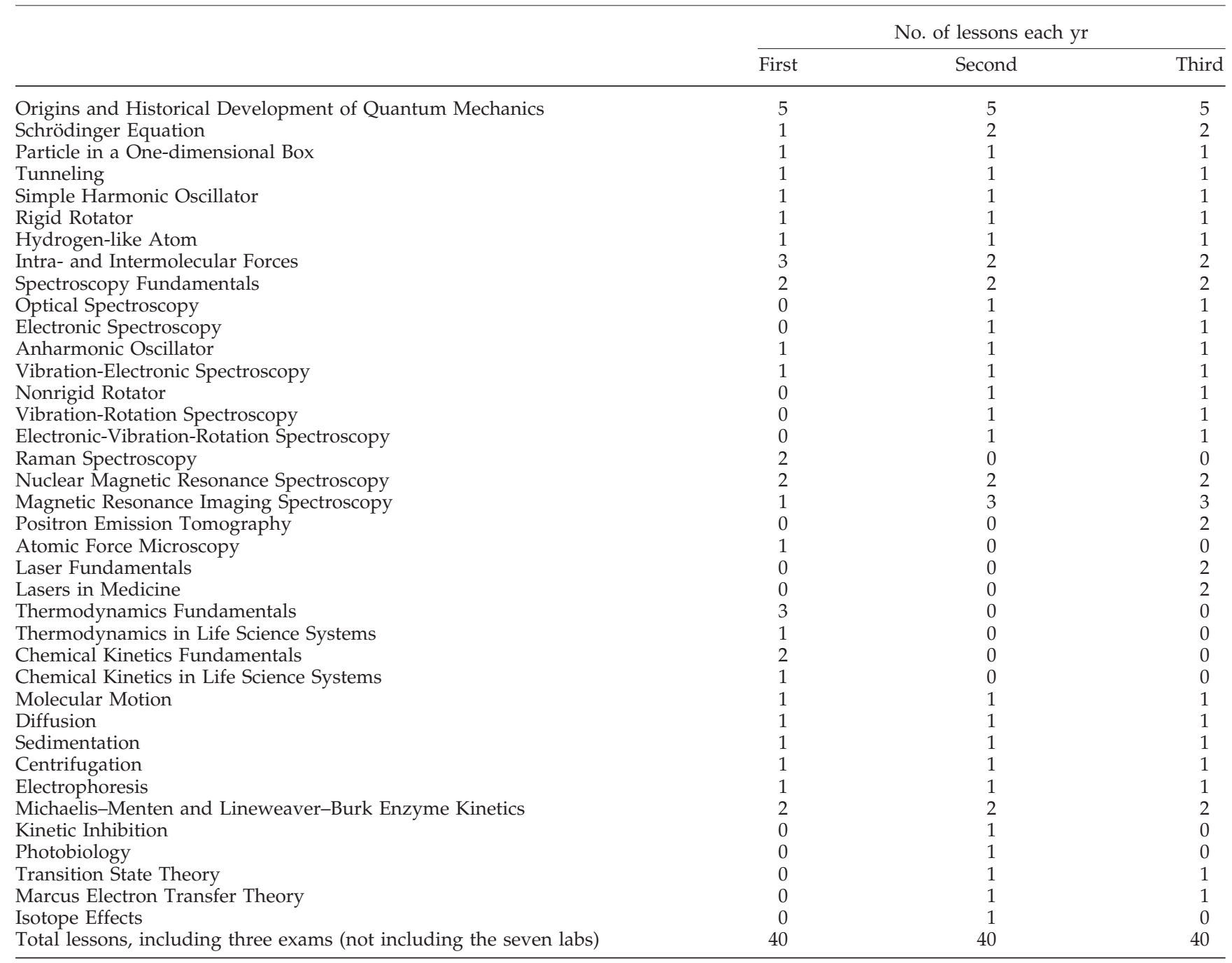

"This is only the third course that I have taken here that stimulated me intellectually (Modern Physics, Orgo are the other two). In general, I appreciate its difficulty as a challenge, and it motivated me to really try and understand the material, as opposed to the normal spec and dump [memorize and forget] study method."

"This course is applicable to my future because it gave me more critical-thinking skills and taught me to apply a lot of knowledge that I have learned in other life science classes."

Table 3. Student survey results of course impressions

The course

\begin{tabular}{|c|c|c|c|c|c|c|c|c|c|c|c|}
\hline \multicolumn{6}{|c|}{ Year 1} & \multicolumn{6}{|c|}{ Year 2} \\
\hline SA & A & $\mathrm{N}$ & $\mathrm{D}$ & SD & $\mathrm{SA}+\mathrm{A}$ & SA & A & $\mathrm{N}$ & D & SD & $\mathrm{SA}+\mathrm{A}$ \\
\hline 24 & 54 & 20 & 2 & 0 & 78 & 63 & 25 & 13 & 0 & 0 & 88 \\
\hline 24 & 49 & 22 & 5 & 0 & 73 & 54 & 33 & 13 & 0 & 0 & 87 \\
\hline 22 & 29 & 17 & 22 & 10 & 51 & 33 & 29 & 25 & 4 & 8 & 62 \\
\hline 34 & 37 & 17 & 10 & 2 & 71 & 38 & 42 & 17 & 4 & 0 & 80 \\
\hline 24 & 39 & 27 & 10 & 0 & 63 & 38 & 50 & 13 & 0 & 0 & 88 \\
\hline
\end{tabular}

a. Was stimulating and challenging

b. Increased my critical-thinking ability

c. Increased my motivation to continue learning

d. Encouraged collaborative learning by students

e. Labs supported and reinforced the class

gree (A), are neutral (N), disagree (D), and strongly disagree (SD). 
Table 4. Student survey results of course outcome goals

\begin{tabular}{|c|c|c|c|c|c|c|c|c|c|c|c|c|}
\hline \multirow{2}{*}{ Goal } & \multicolumn{6}{|c|}{ I accomplished the course outcome goal of year 1} & \multicolumn{6}{|c|}{ I accomplished the course outcome goal of year 2} \\
\hline & SA & A & $\mathrm{N}$ & $\mathrm{D}$ & SD & $\mathrm{SA}+\mathrm{A}$ & SA & A & $\mathrm{N}$ & $\mathrm{D}$ & SD & $\mathrm{SA}+\mathrm{A}$ \\
\hline 1 & 17 & 46 & 24 & 12 & 0 & 63 & 17 & 71 & 8 & 4 & 0 & 88 \\
\hline 2 & 10 & 61 & 20 & 10 & 0 & 71 & 13 & 83 & 4 & 0 & 0 & 96 \\
\hline 3 & 12 & 54 & 27 & 7 & 0 & 66 & 13 & 75 & 4 & 4 & 0 & 88 \\
\hline 4 & 10 & 56 & 27 & 7 & 0 & 66 & 8 & 75 & 8 & 8 & 0 & 83 \\
\hline 5 & 20 & 41 & 32 & 0 & 7 & 61 & 29 & 63 & 8 & 0 & 0 & 92 \\
\hline
\end{tabular}

Percentages of students who strongly agree (SA), agree (A), are neutral (N), disagree (D), and strongly disagree (SD).

"I think this course is applicable to my future because it forces one to think outside the box, the one with the particle in it. Really, it sparked interest in the reasoning behind chemistry equations and stimulated my critical thinking and problem solving abilities."

"The lab really helped me understand a lot of the theories we learned in class. There was not a lab for everything, but the concepts that were tested on the labs were the ones that I understood the best."

"Don't take it. Go for additional instruction. Do the homework. Ask lots of questions."

"For those of us applying to medical school, this grade will be seen. Have to curve the grades."

"This is the most dissatisfying course I have taken in my major. I did not see its relevance."

"I am a life science major. This course is useless for me. Let a chemistry major take it."

"This course was extremely challenging and it's been a great accomplishment completing it."

"As much as I tried to convince myself that I would need to learn the material to become a good physician, I was just never fully convinced of it."

"My classmates were my lifesavers during this course. I could not have made it through without collaboration during board problems, study groups before assignments or graded events, or lab partners to reassure me I was on the right track."

"Just do it, all the hype doesn't mean it's that bad, and remember that the person next to you will be sucking just as bad the whole time."

Table 5. Instructor assessment of student achievement of course outcome goals

\begin{tabular}{lrrrrr}
\hline \multirow{2}{*}{ Objective } & \multicolumn{2}{c}{ Yr 1 } & & \multicolumn{2}{c}{ Yr 2 } \\
\cline { 2 - 3 } \cline { 5 - 5 } & Avg. & SD & & Avg. & SD \\
\hline 1 & 69.6 & 17.2 & & 77.8 & 9.6 \\
2 & 67.7 & 14.7 & & 77.3 & 13.3 \\
3 & 67.7 & 14.7 & 76.9 & 11.8 \\
4 & 73.9 & 15.1 & 76.9 & 11.8 \\
5 & 94.2 & 3.9 & 96.1 & 4.2 \\
\hline
\end{tabular}

Cumulative percentage score on graded exams and labs, as aligned with course outcome goals.
There is no doubt that the course was a challenging, rigorous presentation of physical chemistry concepts. Students appreciated the challenge and the result-an enhanced appreciation and understanding of life science from a fundamental, quantitative perspective.

\section{CONCLUSIONS}

As indicated by the assessment, student satisfaction and success increased from first to second year as the course evolved into one shaped by student feedback. Students overwhelmingly supported the small section sizes rather than a single, large section. The planned third year of the course includes even more health-related topics, and anticipation is that the positive trend will continue. Of the second year student cohort, 17 students went directly to medical school upon graduation. Of this medical school cohort, $67 \%$ agreed that the course was relevant to their future as a physician. For those intending future graduate school attendance, $71 \%$ found the course relevant. These results are particularly welcome as, based on instructor experience, undergraduate life science majors question the rationale for a required physical chemistry course. After completing the course, however, a significant majority found that the knowledge, skills, and abilities they had learned in the course were relevant to their future professional pursuits. In conclusion, the approach to designing and implementing the Physical Chemistry for Life Science course proved successful. Student resistance to physical chemistry was reduced, presumably through the stakeholder effect as students drove the evolution of the course to one more aligned with their life science interests. As the course evolved, students perceived they had better achieved the course outcome goals, and instructor assessment of their performance on exams supports this perception. As a result, students were stimulated and challenged through the study and application of mathematics and physical science concepts in their life science program of study.

\section{ACKNOWLEDGMENTS}

This article is based on the 2-yr period during which I designed, instructed, and assessed the new Physical Chemistry for Life Science course for the Department of Chemistry and Life Science at the United States Military Academy at West Point. I have since retired from the Army and joined the faculty of Georgia Gwinnett College. 


\section{REFERENCES}

Atkins, P., and de Paula, J. (2001). Physical Chemistry, 7th ed., New York: W. H. Freeman.

Atkins, P., and de Paula, J. (2006). Physical Chemistry for the Life Sciences, New York: W. H. Freeman.

Bell, E. (2003). Implementing the American Society for Biochemistry and Molecular Biology recommended curriculum in a biochemistry and molecular biology degree program hosted jointly by a chemistry and biology department. Biochem. Mol. Biol. Educ. 31, 225.

Bialek, W., and Botstein, D. (2004). Introductory science and mathematics education for 21st-century biologists. Science 303, 788-790.

Boyle, J. (2003). Implementing the recommended curriculum in a biochemistry and molecular biology degree program in a biochemistry and molecular biology department. Biochem. Mol. Biol. Educ. $31,283$.

Derrick, M., and Derrick, F. (2002). Predictors of success in physical chemistry. J. Chem. Educ. 79, 1013-1016.

Dougherty, R. (1997). Grade/performance contracts, enhanced communication: effects on student performance, retention, and attitudes in general chemistry. J. Chem. Educ. 74, 722

Ertwine, D., and Palladino, G. (1987). The Thayer concept vs. lecture, an alternative to PSI. J. Coll. Sci. Teach. 16, 524.

Gross, L., Brent, R., and Hoy, R. (2004). The interface of mathematics and biology. Cell Biol. Educ. 3, 85-92.

Hahn, K., and Polik, W. (2004). Factors influencing success in physical chemistry. J. Chem. Educ. 81, 567-572.

Hammes, G. (2007). Physical Chemistry for the Biological Sciences, Hoboken, NJ: John Wiley \& Sons.

Kennedy, D., and Gentile, J. (2003). Is Bio2010 the right blueprint for the biology of the future? Cell Biol. Educ. 2, 224-227.
May, R. (2004). Uses and abuses of mathematics in biology. Science 303, 790-793.

Nicoll, G., and Francisco, J. (2001). An investigation of the factors influencing student performance in physical chemistry. J. Chem. Educ. 78, 99-102.

National Research Council (2003). BIO2010, Transforming Undergraduate Education for Future Research Biologists, Washington, DC: National Academies Press. http://books.nap.edu/catalog/ 10497.html (accessed 23 December 2008).

Office of the Dean, United States Military Academy (2002). Educating Future Army Officers for a Changing World. www.dean. usma.edu/ DeansCorner/default.cfm (accessed 23 December 2008).

Office of Policy, Planning, and Analysis, United States Military Academy (2000). Strategic Vision 2010. www.usma.edu/ superintendent/ letters/christman/Briefs/Vision2010/vision2010.pdf (accessed 23 December 2008).

Slonczewski, J., and Marusak, R. (2004). A response to BIO 2010, transforming undergraduate education for future research biologists, from the perspective of the biochemistry and molecular biology major program at Kenyon College. Biochem. Mol. Biol. Educ. 32, 151-155.

Sözbilir, M. (2004). What makes physical chemistry difficult? J. Chem. Educ. 81, 573-578.

Steitz, J. (2003). Bio2010-New challenges for biology educators. Cell Biol. Educ. 2, 87-91.

The Teaching Professor (2003). Syllabus quiz reduces misunderstandings down the road, 17, 2 .

Tinoco, I., Sauer, K., Wang, J., and Puglisi, J. (2002). Physical Chemistry: Principles and Applications in Biological Sciences, Upper Saddle River, NJ: Prentice Hall.

Toth, L., and Montagna, L. (2002). Class size and achievement in higher education: a summary of current research. Coll. Stud. J. 36, 253. 